Chem Commun (Camb). 2017 August 11; 53(62): 8774-8777. doi:10.1039/c7cc04895e.

\title{
Using anion recognition to control the folding and unfolding of a single chain phosphorescent polymer
}

\author{
Xiaofan Ji, Chenxing Guo, Xian-Sheng Ke, Xiaodong Chi, and Jonathan L. Sessler \\ Department of Chemistry, 105 East 24th Street, Stop A5300, The University of Texas at Austin, \\ Austin, Texas 78712, United States
}

\begin{abstract}
We report here the use of anion recognition to control the folding and unfolding of single polymeric chain consisting of a PMMA bearing pendant calix[4]pyrrole and $\mathrm{Pt}(\mathrm{II})$ porphyrin subunits.
\end{abstract}

\section{TOC Graphic}
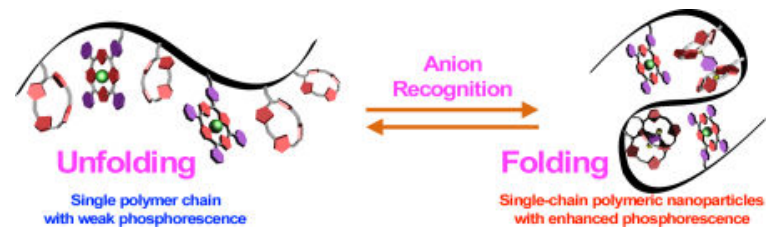

Calix[4]pyrrole-based anion recognition allows control over the folding and unfolding of a single PMMA polymeric chain bearing pendant calix[4]pyrrole and Pt(II) porphyrin subunits.

So-called single-chain polymeric nanoparticles (SCPNs) have attracted attention because they typically form structures that are relatively small ( $\leq 20 \mathrm{~nm}$ ) as compared to traditional nanoparticles prepared by microemulsion polymerization or the self-assembly of amphiphiles (which give NPs that are $\geq 20-200 \mathrm{~nm}$ in size). ${ }^{1}$ SCPNs are typically formed by intramolecular cross-linking or by collapsing a single coil of polymer chain in dilute solution. ${ }^{1}$ To date, many noncovalent interactions have been exploited as reversible intramolecular forces to control the folding/unfolding of SCPNs. ${ }^{2}$ For instance, Meijer and coworkers developed a series of 2-uriedopyrimidinone (UPy) dimerization-based SCPNs. By controlling the hydrogen bonding sites in the UPy units, the ability of a single polymer chain to form SCPNs could be tuned..$^{2 a, b}$ Metal coordination, with a primary focus on rhodium and copper, has been used to cross-link polymers to form SCNPs. ${ }^{2 c, d}$ For example, Palmans and co-workers grafted polynorbornene with 3,3-bis(acylamino)-2,2-bipyridine substituted benzene-1,3,5-tricarboxamides (BiPy-BTAs). Driven by presumed intramolecularly $\pi-\pi$ interactions, these polymers were found to fold into fluorescent nanoparticles whose

Correspondence to: Jonathan L. Sessler.

Electronic Supplementary Information (ESI) available: [details of any supplementary information available should be included here]. See DOI: $10.1039 / \mathrm{x} 0 \mathrm{xx} 00000 \mathrm{x}$

The authors attest that there are no conflicts of interest. 
emissive features could be quenched by the addition of copper. ${ }^{2 \mathrm{~d}}$ Scherman et al. functionalized polymers with methyl viologen and naphthyl groups and showed that the addition of cucurbit[n]urils produced ternary host-guest complexes and promoted the formation of SCNPs. ${ }^{2 \mathrm{e}}$ Barner-Kowollik and co-workers recently reported SCPNs formed from the self-assembly of an ABCD-type tetrablock copolymer driven by a combination of benzo-21-crown-7/secondary ammonium salt host-guest interactions and those involving the Hamilton wedge/cyanuric acid hydrogen-bonding motif. ${ }^{2 \mathrm{f}}$ However, to our knowledge, anion recognition has yet to be explored as a means of controlling SCNP formation.

Anions play critical roles in a number of areas, including biology, pharmacy, and environmental sciences. ${ }^{3}$ In recent years, considerable effort has been devoted to the problems associated with anion recognition. Chemosensors that are able to detect the presence of anionic guests through, e.g., concentration dependent optical or electrochemical changes represent one point of focus. ${ }^{3 \mathrm{~b}}$ Another is separation, where extractants are being pursued with the goal of removing toxic or unwanted anions from aqueous environments. ${ }^{3 c}$ In addition, attention has been devoted recently to transporters, potential therapeutic agents capable of ferrying anions across phospholipid membranes. ${ }^{3 \mathrm{~d}}$ Anion binding has also been exploited successfully in the area of organocatalysis. ${ }^{3 e}$ The importance of anion recognition has now led us to explore whether differences in anion binding can be used to control the formation and disassembly of SCPNs. Here, we report single chain polymers incorporating both calix[4]pyrrole anion recognition subunits and $\mathrm{Pt}$ (II) porphyrin phosphorescent readout elements and show that their folding and unfolding may be controlled through differences in anion binding.

Calix[4]pyrroles are recognized anion receptors. Typically, this class of receptors binds anions via pyrrole $\mathrm{NH}$-anion hydrogen bonds, which induces conversion from the 1,3alternate to the cone conformation. ${ }^{3 \mathrm{a}, 3 \mathrm{f}}$ We have previously found that calix[4]pyrrolecontaining polymers could be cross-linked by adding appropriate dianions. ${ }^{4}$ Our design concept, shown in Scheme 1, is predicated on the thinking that the competitive anion would disrupt this interaction, leading to an opening up of the SCPNs formed through crosslinking. Adding a signalling agent, in the present instance a phosphorescent $\mathrm{Pt}(\mathrm{II})$ porphyrin, would then allow visual observation of the folding and unfolding process.

$\mathrm{Pt}(\mathrm{II})$ porphyrins are attractive signalling agents due to their bright phosphorescence, longlived excited-state lifetimes, and high stability. ${ }^{5}$ However, their emission is typically quenched in the presence of oxygen. ${ }^{5 \mathrm{~b}}$ It was thus expected that the folded SCPN, wherein the $\mathrm{Pt}(\mathrm{II})$ subunits are relatively well protected from oxygen, would be more emissive and that an open chain form, presumably stabilized through competitive anion recognition, would be less emissive. This would allow for the direct visual monitoring of the folding process and SCPN formation that is presumed to be induced by anion recognition.

To test the above hypothesis, a poly(methyl methacrylate) (PMMA) polymer containing pendant calix[4]pyrrole and $\mathrm{Pt}(\mathrm{II})$ porphyrin groups (polymer 1) was prepared by subjecting methacrylate-derived calix[4]pyrrole and Pt(II) porphyrin monomers to free radical copolymerization in the presence of methyl methacrylate (Scheme S1 and Fig. S1-S3, ESI $\dagger$ ). Briefly, methyl methacrylate, $10 \mathrm{~mol} \%$ of the calix[4]pyrrole monomer, $5 \mathrm{~mol} \%$ of 
the $\mathrm{Pt}(\mathrm{II})$ porphyrin monomer, and $1 \mathrm{~mol} \%$ of azobisisobutyronitrile (AIBN) were dissolved in dry DMF and subjected to three freeze/pump/thaw cycles. The reaction mixture was then heated to $70{ }^{\circ} \mathrm{C}$, stirred overnight, and finally precipitated from a large excess of cold methanol to yield polymer $\mathbf{1}$ as a dark red powder. GPC analysis revealed that $\mathbf{1}$ had an average molecular weight of $25.8 \mathrm{kDa}$ and a molar mass dispersity of 1.66. As inferred from ${ }^{1} \mathrm{H}$ NMR spectroscopic studies, the ratio of $\mathrm{Pt}(\mathrm{II})$ porphyrin, unsubstituted methyl methacrylate, and calix[4]pyrrole repeat units within the polymer chain was 6.7: 141: 10 .

Upon mixing with the terephthalate dianion 2 (as its bis(tetrabutylammonium (TBA) salt), in dilute chloroform, the polymer undergoes intramolecular supramolecular cross-linking. This results in the formation of SCPNs. Enhanced phosphorescence is seen for the SCPNs compared to what is observed for the extended form of the polymer, an effect ascribed to reduced contact between the $\mathrm{Pt}(\mathrm{II})$ porphyrin moieties and molecular oxygen. ${ }^{5}$ Exposure to a competitive anion in dilute chloroform was expected to displace some or all of the bound terephthalate anion cross-linkers and lead to an opening up of the aggregated SCPN form. In fact, in the case of various test anions $\left(\mathrm{F}^{-}, \mathrm{Cl}^{-}, \mathrm{H}_{2} \mathrm{PO}_{4}^{-}, \mathrm{HSO}_{4}^{-}, \mathrm{Br}^{-}, \mathrm{NO}_{3}^{-}\right.$; as their TBA salts), such exposure leads to a decrease in the phosphorescence intensity. This observation was taken as initial evidence that calix[4]pyrrole-anion interactions can be used to control the folding and unfolding of single polymer chains, and would be accompanied by phosphorescence intensity change.

To characterize polymer 1 further and study its interaction with anions in greater detail, ${ }^{1} \mathrm{H}$ NMR spectral analyses were carried out in $\mathrm{CDCl}_{3}$, a solvent in which $\mathbf{1}$ and various TBA anion salts were soluble. Initially, the complexation between calix[4]pyrrole and TBA benzoate was investigated (Fig. 1). The proton NMR spectra of calix[4]pyrrole, TBA benzoate, and their equimolar mixture (Fig. 1b-1d) revealed features consistent with a system in which complexation occurs. For instance, as expected for the formation of a hydrogen bond stabilized complex, downfield shifts in the pyrrolic $\mathrm{NH}$ proton signals $\left(\mathrm{H}_{1}\right)$ were observed (from $7.00 \mathrm{ppm}$ to $7.12 \mathrm{ppm}$ ) upon treating calix[4]pyrrole with TBA benzoate. Likewise, shifts in the aromatic proton signals $\left(\mathrm{H}_{2}, \mathrm{H}_{3}\right.$ and $\left.\mathrm{H}_{4}\right)$ corresponding to the benzoate anion were seen: $\mathrm{The}_{2} \mathrm{H}_{2}$ signals shifted from their initial values of 8.12-8.08 ppm to 8.18 and $8.15 \mathrm{ppm}$, whereas the $\mathrm{H}_{3}$ and $\mathrm{H}_{4}$ signals shifted from their initial value of $7.30-7.38 \mathrm{ppm}$ to $7.68,7.53$, and 7.32-7.28 ppm. These results are consistent with the presence of H-bonding interactions between the pyrrole moieties of the calix[4]pyrrole receptor and the benzoate anion.

When an equimolar quantity of a potentially competitive anion salt, specifically $\mathrm{TBAHSO}_{4}$, TBAF, TBACl, $\mathrm{TBABr}, \mathrm{TBANO}_{3}$, and $\mathrm{TBAH}_{2} \mathrm{PO}_{4}$, was included in the 1:1 calix[4]pyrrole and TBA benzoate $\mathrm{CDCl}_{3}$ mixture, the chemical shifts corresponding to the aromatic protons $\mathrm{H}_{2}, \mathrm{H}_{3}$ and $\mathrm{H}_{4}$ of TBA benzoate returned to their uncomplexed values; however, the signals for pyrrolic NH protons shifted to different positions (Fig. 1). These NMR spectral findings were taken as evidence that in this solvent and for these salt forms, these additional anions effectively outcompete the benzoate anion for the calix[4]pyrrole anion receptor, albeit with different degrees of efficacy. This displacement efficacy was found to correlate well with the inherent anion affinities of calix[4]pyrrole in halogenated solvents, namely $\mathrm{F}^{-}$ $>\mathrm{Cl}^{-}>\mathrm{H}_{2} \mathrm{PO}_{4}^{-}>\mathrm{HSO}_{4}^{-}, \mathrm{Br}^{-}$, and $\mathrm{NO}_{3}{ }^{-} \cdot 3 \mathrm{f}$ 
We next studied the ability of the linear polymer 1 to self-fold into an SCPN as the result of calix[4]pyrrole-based anion recognition. We recently reported that polymers with pendent calix[4]pyrrole groups undergo supramolecular crosslinking upon exposure to dianionic species, such as the terephthalate dianion. ${ }^{4}$ However, typically SCPNs are formed as the result of intra-, rather than intermolecular cross-linking, as observed in the context of our previous report. ${ }^{1,6}$ Therefore, concentration-dependent studies were carried out in an effort to determine whether the terephthalate anion (2) could be used to induce cross-linking of polymer 1 under conditions that favour SCPN formation (Fig. 2a). With this goal in mind, we explored concentrations much lower than those investigated previously.

For a mixture of $\mathbf{1}$ and $\mathbf{2}$ (1:1 molar ratio based on the number of recognition groups), solution viscosities (Fig. 2b) were measured vs concentration using a Cannon-Ubbelohde semi-micro dilution viscometer. As the polymer concentration decreased from $10.0 \mathrm{mg} / \mathrm{mL}$ to $0.10 \mathrm{mg} / \mathrm{mL}$, the specific viscosities of the solution were likewise found to decrease monotonically. However, in the range from $10.0 \mathrm{mg} / \mathrm{mL}$ to $2.0 \mathrm{mg} / \mathrm{mL}$, the viscosity change was obviously larger than over the $2.0 \mathrm{mg} / \mathrm{mL}$ to $0.1 \mathrm{mg} / \mathrm{mL}$ concentration regime. Twodimensional diffusion-ordered ${ }^{1} \mathrm{H}$ NMR spectroscopy (DOSY) experiments were also performed to investigate the self-assembly behaviour of the mixture (Fig. 2c, and Fig. S8$\mathrm{S} 14, \mathrm{ESI} \dagger)$. As the concentration decreased, the measured weight average diffusion coefficients increased gradually. Again, the changes over the $2.0 \mathrm{mg} / \mathrm{mL}$ to $0.2 \mathrm{mg} / \mathrm{mL}$ concentration range were smaller than those over the $10.0 \mathrm{mg} / \mathrm{mL}$ to $2.0 \mathrm{mg} / \mathrm{mL}$ regime. The average diameters of the aggregates were calculated based on the experimentally determined DOSY values (Fig. 2d). ${ }^{2 \mathrm{f}}$ From $0.2 \mathrm{mg} / \mathrm{mL}$ to $2.0 \mathrm{mg} / \mathrm{mL}$, the diameter was around $2 \mathrm{~nm}$; however, when the concentration increased to $10.0 \mathrm{mg} / \mathrm{mL}$, the calculated diameter increased to about $3 \mathrm{~nm}$. Dynamic light scattering (DLS) was also used to calculate the diameter of the aggregates. ${ }^{1,2}$ The results obtained proved concordant with those obtained from the DOSY studies (Fig. 2e, and Fig. S15-S21, ESI $\dagger$ ). Taken in concert, these analyses provide support for a transition from a high concentration regime where intermolecular crosslinking dominates to one in which intramolecular folding is favoured. At concentration of about $\leq 2.0 \mathrm{mg} / \mathrm{mL}$ intramolecular folding dominates and stable nanoparticles (SCPNs) are formed.

Transmission electron microscopy (TEM) provided further support for the formation of SCPNs in dilute solution. As shown in Fig. 3a, the spherically shaped SCPNs were homogeneous and about $2 \mathrm{~nm}$ in size, in agreement with the DOSY and DLS results. The phosphorescence of SCPNs is visible to the naked eye (Fig. 3b). Phosphorescence spectral studies provided further support for terephthalate anion addition promoting SCPN formation. As can be seen from an inspection of Fig. 3c, when excited at $402 \mathrm{~nm}$ (Fig. S3, ESI $\dagger)$, polymer $1(1.0 \mathrm{mg} / \mathrm{mL}, 0.0387 \mathrm{mM})$ on its own was characterized by little phosphorescence intensity. However, enhanced phosphorescence, with a $\lambda_{\mathrm{em}}=670 \mathrm{~nm}$, is seen upon treating with 2 (0.194 mM) (Fig. 3c).

As inferred from the competitive model studies discussed above (cf. Fig. 1), we expected that a number of anions could be used to convert the SCPNs formed from $\mathbf{1}$ and $\mathbf{2}$ into the corresponding open chain polymeric forms. Because it binds relatively weakly to 
calix[4]pyrrole and thus represents a particularly stringent test of our design expectations, we elected to focus in detail on the $\mathrm{HSO}_{4}{ }^{-}$anion. ${ }^{7,8}$

The ability of the SCPNs created by mixing $1(1.0 \mathrm{mg} / \mathrm{mL}, 0.0387 \mathrm{mM})$ with $2(0.194 \mathrm{mM})$ to unfold upon treatment with $\mathrm{HSO}_{4}{ }^{-}$was probed further by monitoring the viscosity, diameter, and phosphorescent intensity changes seen upon adding increasing quantities of $\mathrm{TBAHSO}_{4}$ (cf. Figs. 3d and 3e). The solution specific viscosity increased from 0.063 to 0.23 upon the addition of 1.0 equiv of $\mathrm{TBAHSO}_{4}(0.387 \mathrm{mM})$ (Fig. 3d). The diameter of the aggregates, as determined by DLS (Fig. 3e, and Figs. S22-S26, ESI $\dagger$ ), also increased under these conditions (from 2.0 to $3.3 \mathrm{~nm}$ ). Addition of $\mathrm{TBAHSO}_{4}$ also served to quench the emission intensity (Fig. 3f). Further additions had little appreciable effect. These findings are rationalized in terms the individual polymer chains of $\mathbf{1}$ produced upon disassembly being able to intertwine with one another so as to make the system as a whole more viscous and other movement harder and slower. The additions of other competitive anions also led to an increase in the viscosity of the ensemble (Fig. S27, ESI $\uparrow$ ), a result ascribed to their ability to unfold the SCPNs.

The phosphorescence features of the single chain polymer and the SCPNs was tested (Fig. $\mathrm{S} 28, \mathrm{ESI} \dagger)$. The influence of monomer ratio on the folding/unfolding process was studied (Fig.S29, ESI $\dagger$ ) and several other anions were found to mimic what was found in the case of 2 (cf. Fig. S30, ESI $\dagger$ ).

In summary, we report here the folding and unfolding of a single polymeric chain consisting of a PMMA backbone bearing pendant calix[4]pyrrole and $\mathrm{Pt}(\mathrm{II})$ porphyrin subunits that is triggered via anion recognition. Upon mixing polymer (1) with TBA terephthalate in chloroform at low total concentrations, folding occurs to produce SCPNs. This folding is driven by calix[4]pyrrole-anion interactions and gives rise to SCPNs that produce a readily detectable phosphorescence signal. This signal is, in turn, quenched upon exposure to a competitive anion. The present SCPNs are thus of interest as functional materials whose features are controlled by anion recognition and whose form, compact or disassembled, may be monitored readily by spectroscopic means.

\section{Supplementary Material}

Refer to Web version on PubMed Central for supplementary material.

\section{Acknowledgments}

J.L.S. thanks the U.S. National Institutes of Health (grant GM103790A) for support, as well as the Robert A. Welch Foundation.

\section{Notes and references}

1. Hanlon AM, Lyon CK, Berda EB. Macromolecules. 2016; 49:2.

2. (a) Hosono N, Kushner AM, Chung J, Palmans ARA, Guan Z, Meijer EW. J. Am. Chem. Soc. 2015; 137:6880. [PubMed: 25946315] (b) Liu Y, Pauloehrl T, Presolski SI, Albertazzi L, Palmans ARA, Meijer EW. J. Am. Chem. Soc. 2015; 137:13096. [PubMed: 26388188] (c) Mavila S, Diesendruck CE, Linde S, Amir L, Shikler R, Lemcoff NG. Angew. Chem. Int. Ed. 2013; 52:5767.(d) Gillissen MAJ, Voets IK, Meijer EW, Palmans ARA. Polym. Chem. 2012; 3:3166.(e) Appel EA, Dyson J, del 
Barrio J, Walsh Z, Scherman OA. Angew. Chem. Int. Ed. 2012; 51:4185.(f) Fischer TS, SchulzeSünninghausen D, Luy B, Altintas O, Barner-Kowollik C. Angew. Chem. Int. Ed. 2016; 55:11276. (g) Mavila S, Eivgi O, Berkovich I, Lemcoff NG. Chem. Rev. 2016; 116:878. [PubMed: 26270435]

3. (a) Cai J, Sessler JL. Chem. Soc. Rev. 2014; 43:6198. [PubMed: 24871377] (b) Gale PA, Caltagirone C. Chem. Soc. Rev. 2015; 44:4212. [PubMed: 24975326] (c) Kim SK, Lynch VM, Young NJ, Hay BP, Lee C-H, Kim JS, Moyer BA, Sessler JL. J. Am. Chem. Soc. 2012; 134:20837. [PubMed: 23205692] (d) Gale PA. Acc. Chem. Res. 2011; 44:216. [PubMed: 21207951] (e) Zhang Z, Schreiner PR. Chem. Soc. Rev. 2009; 38:1187. [PubMed: 19421588] (f) Gale PA, Sessler JL, Král V, Lynch V. J. Am. Chem. Soc. 1996; 118:5140.(g) Rostami A, Guérin G, Taylor MS. Macromolecules. 2013; 46:6439.(h) McDonald KP, Qiao B, Twum EB, Lee S, Gamache PJ, Chen C-H, Yi Y, Flood AH. Chem. Commun. 2014; 50:13285.

4. Silver ES, Rambo BM, Bielawski CW, Sessler JL. J. Am. Chem. Soc. 2014; 136:2252. [PubMed: 24443843]

5. (a) Marpu S, Upadhyay PK, Nguyen DT, Oswald IWH, Arvapally RK, Petros RA, Hu Z, Omary MA. J. Phys. Chem. C. 2015; 119:12551.(b) Wang R-F, Peng H-Q, Chen P-Z, Niu L-Y, Gao J-F, Wu L-Z, Tung C-H, Chen Y-Z, Yang Q-Z. Adv. Funct. Mater. 2016; 26:5419.

6. Yan X, Wang F, Zheng B, Huang F. Chem. Soc. Rev. 2012; 41:6042. [PubMed: 22618080]

7. (a) Li Q, Yue Y, Guo Y, Shao S. Sensors and Actuators B. 2012; 173:797.(b) Li P, Zhang Y-M, Lin Q, Li J-Q, Wei T-B. Spectrochimica Acta Part A. 2012; 90:152.

8. Moyer BA, Custelcean R, Hay BP, Sessler JL, Bowman-James K, Day VW, Kang S-O. Inorg. Chem. 2013; 52:3473. [PubMed: 23134587] 
a)
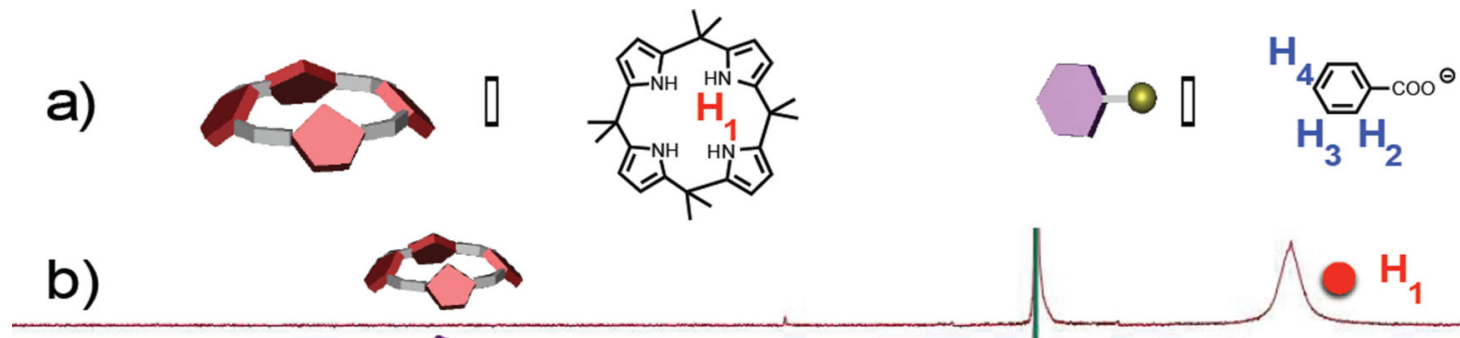

e)

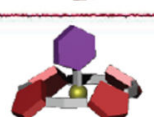

c)

d)
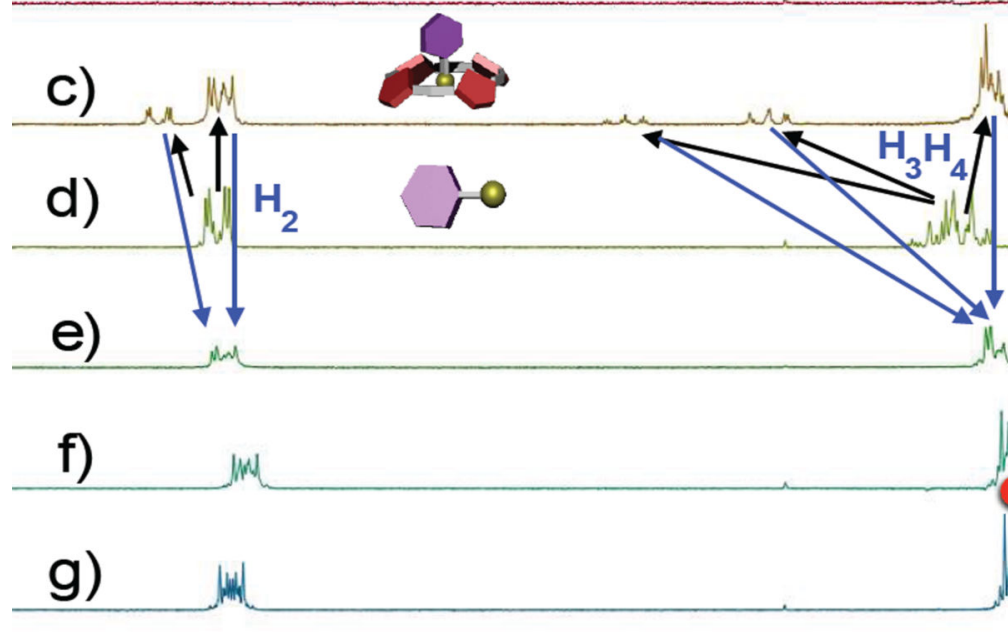

h) $\mu$ w

i) $j$

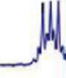

c) $₫ \mathrm{Br}$

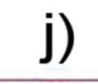
$\operatorname{man}$

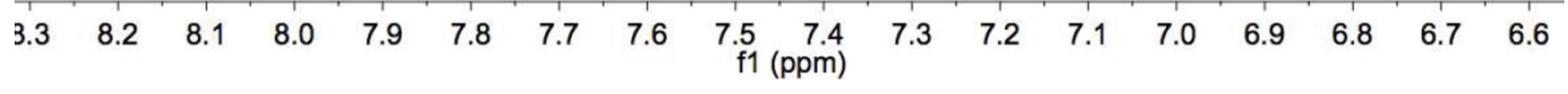

Fig. 1.

(a) Chemical structures and cartoon representation of calix[4]pyrrole and tetrabutylammonium (TBA) benzoate; partial ${ }^{1} \mathrm{H}$ NMR spectra $\left(400 \mathrm{MHz}, \mathrm{CDCl}_{3}, 298 \mathrm{~K}\right)$ :

(b) $5.00 \mathrm{mM}$ calix[4]pyrrole; (c) calix[4]pyrrole and TBA benzoate (5.00 $\mathrm{mM}$ in each); (d) $5.00 \mathrm{mM}$ TBA benzoate solutions; (e) (c) and $5.00 \mathrm{mM} \mathrm{TBAHSO}_{4}$; (f) (c) and $5.00 \mathrm{mM}$ TBAF; (g) (c) and $5.00 \mathrm{mM} \mathrm{TBACl}$; (h) (c) and $5.00 \mathrm{mM} \mathrm{TBABr}$; (i) (c) and $5.00 \mathrm{mM}$ $\mathrm{TBANO}_{3}$; (j) (c) and $5.00 \mathrm{mM} \mathrm{TBAH}{ }_{2} \mathrm{PO}_{4}$. 
a)

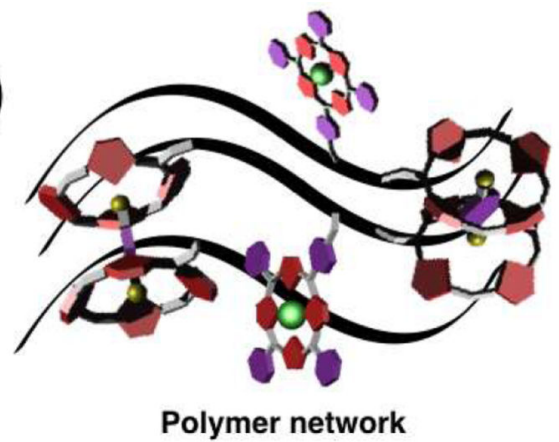

Polymer network
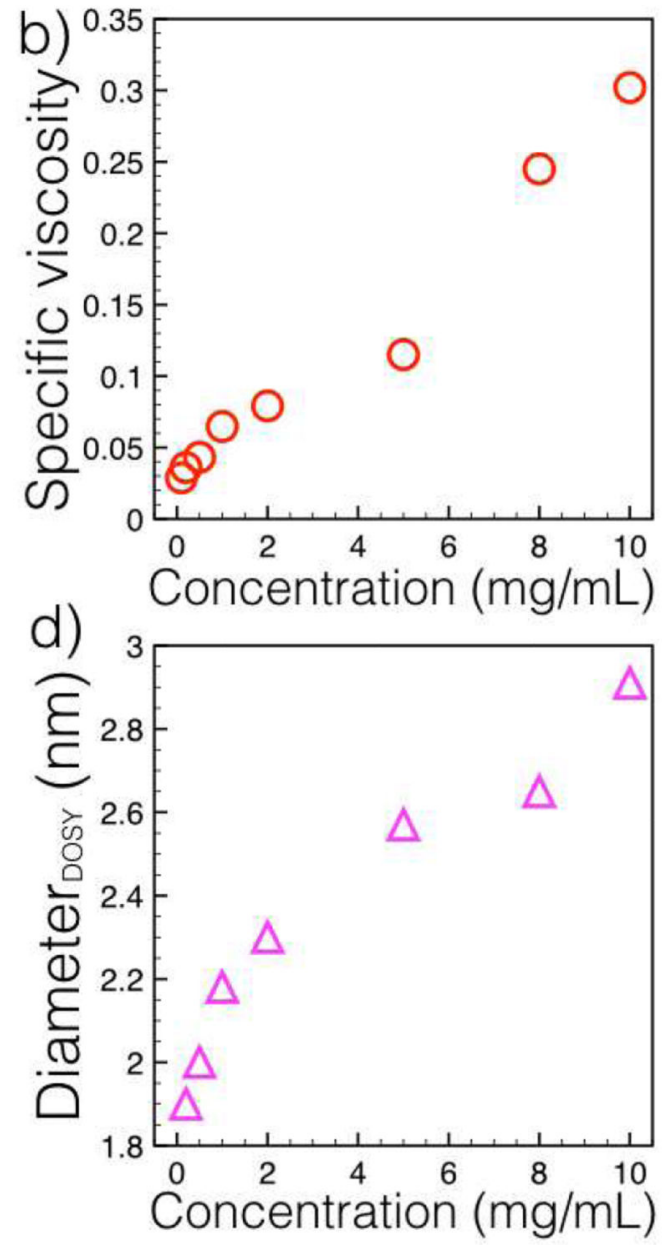

Decreasing concentration

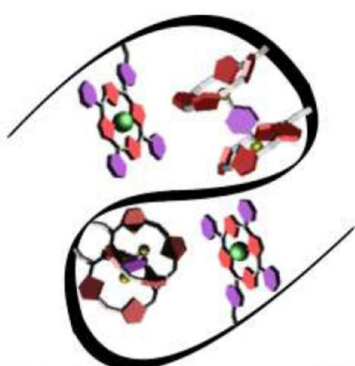

Single-chain polymeric nanoparticles

C)

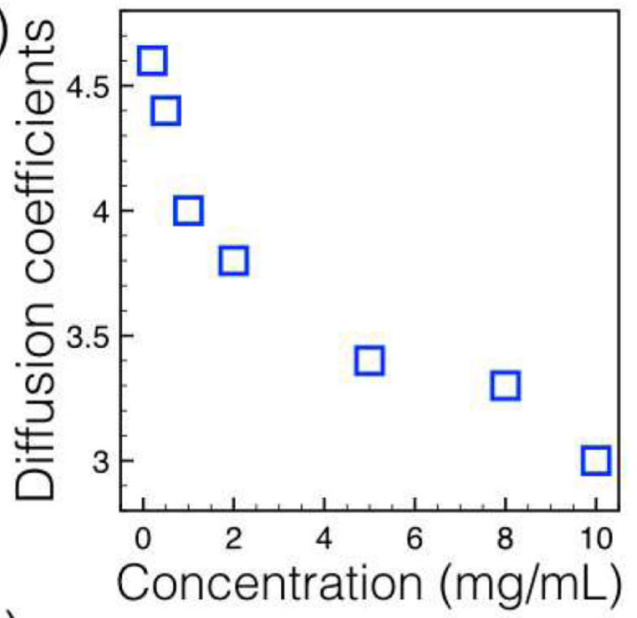

e)

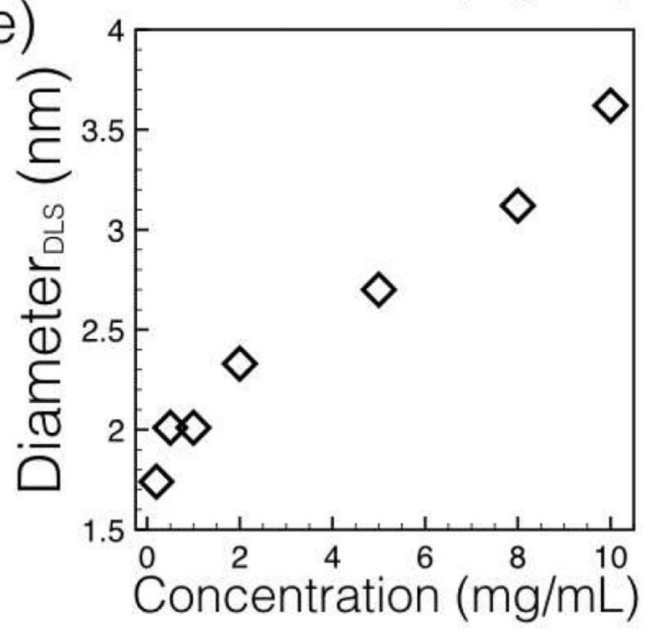

Fig. 2.

(a) Cartoon representation of the concentration dependent transition from intermolecular associated polymeric forms of $\mathbf{1}$ to the corresponding single-chain polymeric nanoparticles (SCPNs) stabilized by intramolecular interactions. (b) Specific viscosities. (c) DOSY values $\left(10^{-10} \mathrm{~m}^{2} \mathrm{~s}^{-1}\right)$. (d) Diameter determined by DOSY (and calculated using the Stokes-Einstein equation). (e) Diameter determined from DLS analyses of mixtures of 1 and 2 (1:1 molar ratio of recognition groups) versus polymer concentration. 

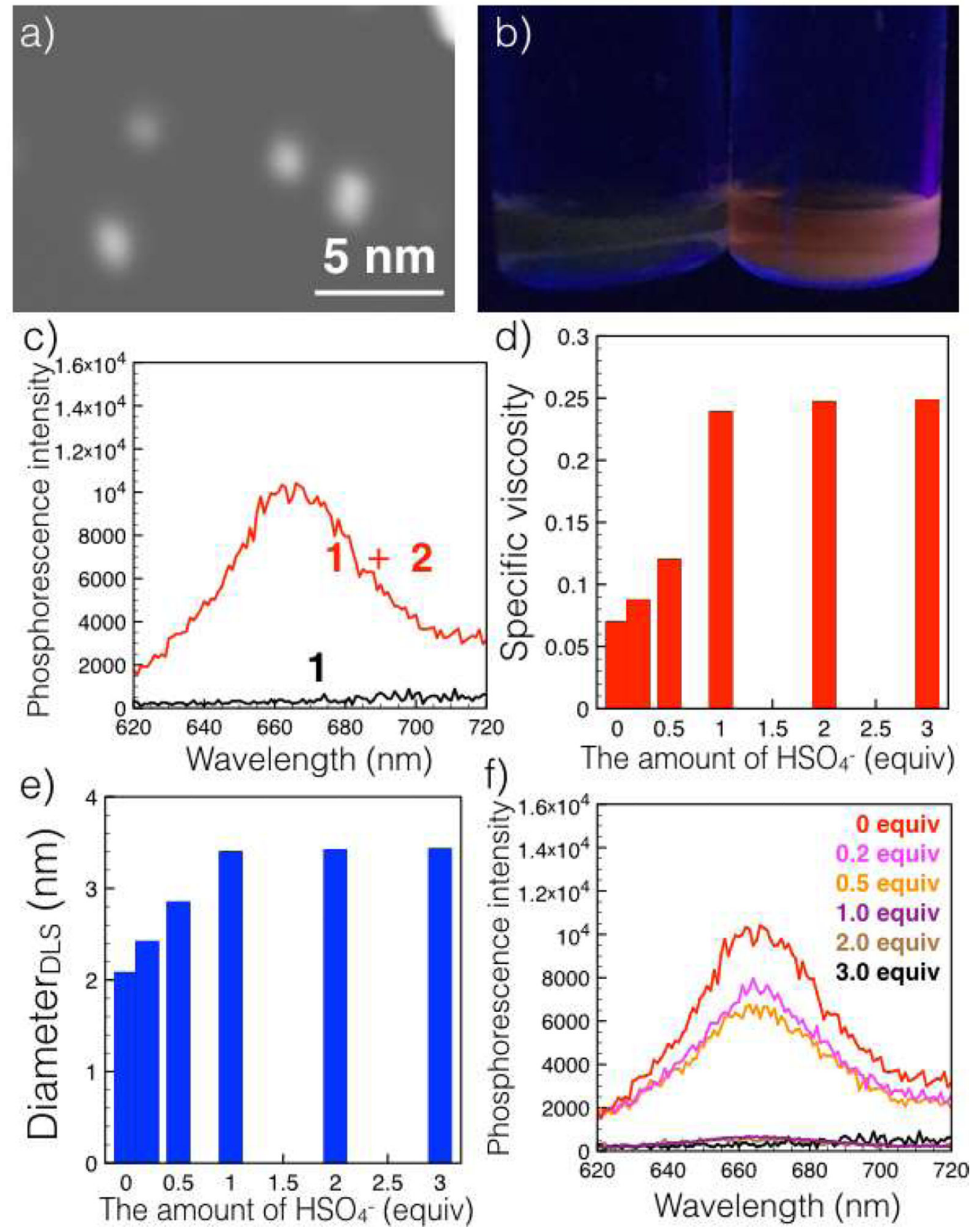

Fig. 3.

(a) TEM image of a mixture of $\mathbf{1}(1.0 \mathrm{mg} / \mathrm{mL}, 0.0387 \mathrm{mM}$, corresponding to a $0.387 \mathrm{mM}$ calix[4]pyrrole subunit concentration per polymer chain) and $\mathbf{2}(0.194 \mathrm{mM})$ in chloroform. (b) Photographs of $\mathbf{1}(1.0 \mathrm{mg} / \mathrm{mL})$ before (left) and after (right) adding $2(0.194 \mathrm{mM})$ taken under illumination with a UV lamp at $365 \mathrm{~nm}$. (c) Phosphorescent spectra $\left(\lambda_{\mathrm{exc}}=402 \mathrm{~nm}\right)$ of $1(1.0 \mathrm{mg} / \mathrm{mL})$ before and after adding $2(0.194 \mathrm{mM})$ as its bis-TBA salt. (d) Specific viscosity, (e) diameter determined by DLS, and (f) phosphorescent spectra $\left(\lambda_{\text {exc }}=402 \mathrm{~nm}\right)$ of mixtures of $\mathbf{1}(1.0 \mathrm{mg} / \mathrm{mL})$ and $\mathbf{2}(0.194 \mathrm{mM})$ observed upon adding increasing $\mathrm{TBAHSO}_{4}$. 


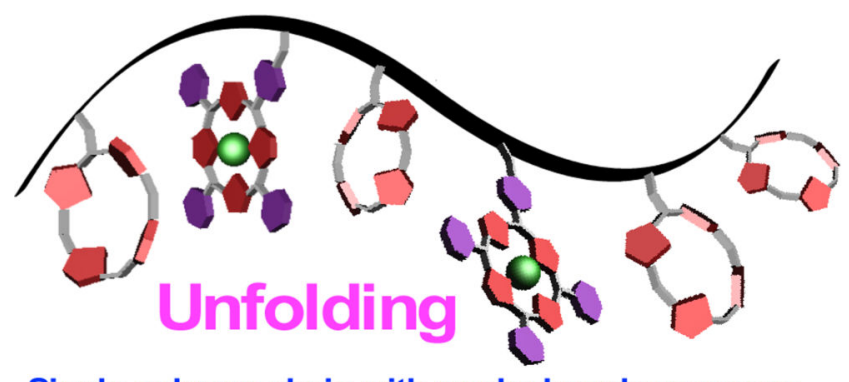

Single polymer chain with weak phosphorescence
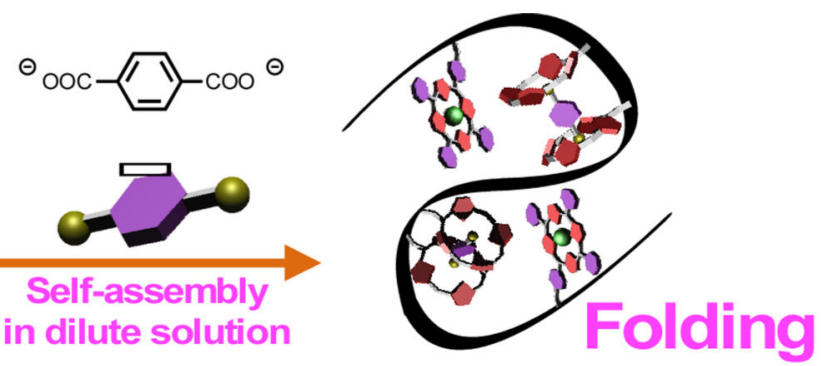

Single-chain polymeric nanoparticles with enhanced phosphorescence
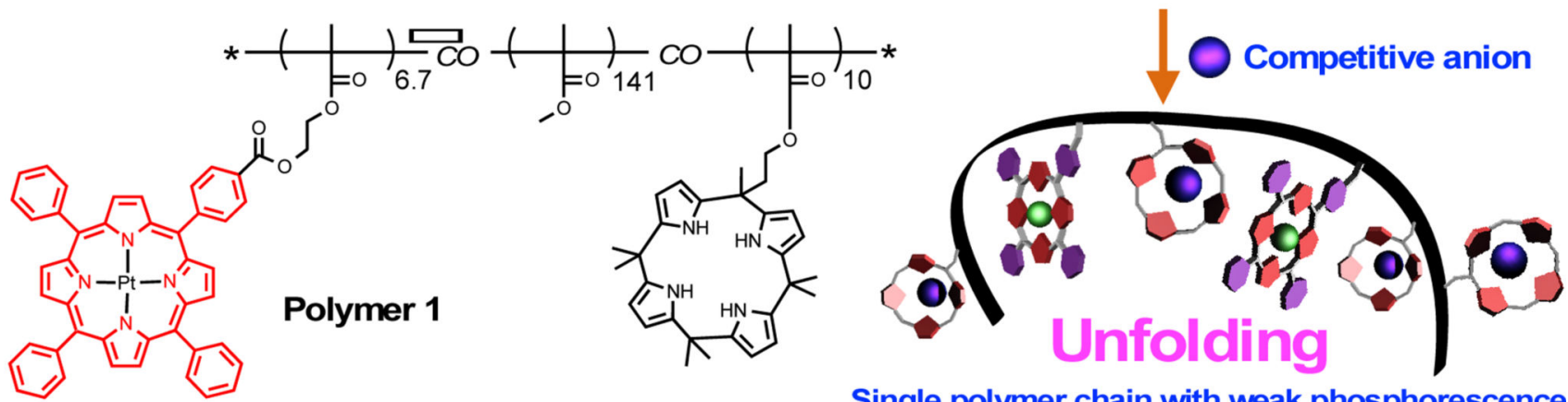

Single polymer chain with weak phosphorescence

Scheme 1.

Chemical structures of polymer $\mathbf{1}$ and cross-linker $\mathbf{2}$. Also shown are cartoon representations of the limiting forms of the polymer and the effects of anion (terephthalate and a competitive anion) on the structure and emissive properties of the system. 